\title{
NOTES ON THE FORMATION AND INHIBITION OF MILDEW IN PAINTS. ${ }^{1}$
}

\author{
BY \\ HENRY A. GARDNER, \\ Assistant Director, The Institute of Industrial Research, Washington, D. C., \\ Member of the Institute.
}

The formation of milclew upon the surface of green paints such as are used so widely upon the exterior trim and shutters of frame buildings has often been observed by the property owner. In damp localities, especially along the sea coast, the mildewing of painted exterior surfaces is not an uncommon sight, and the painter has searched in vain for materials which would prevent such conditions. A good opportunity was recently afforded the writer to study the subject of milrlew, when, during the course of the examination of a red lead paint which had shown a peculiar thickening action, certain types of fungi were discovered. The paint had not hardened up as is usual with pure red lead paints which are kept in containers for a considerable period, but the pigment portion seemed to lave no affinity for the oil in which it was ground, a peculiar gelatinous condition being olserved. Around the edges of the paint a slight film harl formerl, and white spots were olsserved to be present upon the surface of this film. These white spots had the appearance of the type of mould that is often found upon damp basement walls. A portion of the skin was removed and preserved for microscopic examination.

There was obtained a sample of the original linseed oil in which the red learl had been ground, and it was thought advisable to examine this oil as well as the oil floating upon the top of the partially settled pigment, to find ont whether both oils were pure. The analysis of the original oil gave the following results, which indicate that it was pure linseed oil:

Color: Light amber with a distinct green fluorescence. Iodine number ........................ 85.2

${ }^{1}$ Communicated by the author. 


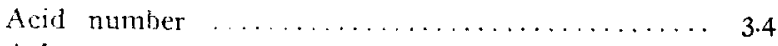

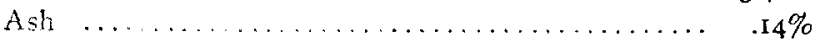

The oil that was poured from the top of the settled red lead pigment har the following constants:

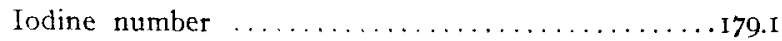

Acid number $\ldots \ldots \ldots \ldots \ldots \ldots \ldots \ldots \ldots \ldots \ldots .6 .6$

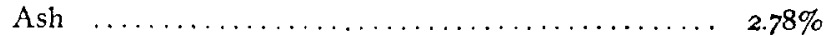

In the latter analysis the lower iodine value and higher acid number and ash presented differences which could easily be accounted for by the action of the red lead upon the oil. The analyses would therefore indicate that both samples of oil were pure. Curious to state, however, the oil that had been poured from the top of the red lead paint had an odor resembling fish oil, and the use of the latter oil might be held accountable for the condition of the paint. After standing in a bottle for forty-eight hours, the oil became very turbid and viscous, air bubbles having developed throughout the mass. Upon the surface of the oil there had formed a slight film which was covered with very small white spots. A portion of the oil was tested to determine whether there was any large amount of free glycerine present. A small amount was found, suggesting that hydrolysis had taken place. Such hydrolysis, however, might be accounted for by the action of the red lead upon the oil, wherein free fatty acid had been formed, accompanied by the splitting off of glycerine.

A more exhaustive test of the sample to determine whether fish oil was present was made according to the method outlined by Eisenschiml. ${ }^{2}$ The original oil and the oil from the top of the can were separately dissolved in a mixture of chloroform and acetic acid and an excess of bromine added to each sample. The test-tubes containing these mixtures were placed in hot water for fifteen minutes. The original oil did not show any precipitated bromides, while the oil from the red lead paint showed a very large quantity. With raw oil, the precipitation of insoluble bromides would constitute a positive test that fish oil was present. It has recently been found, however, that this test is

"Jour. Indus. and Eng. Chem., I9го, p. 43. 
not of great value when applied to the examination of a boiled linseed oil. Inasmuch as the oil from the top of the red lead paint was shown by analysis to contain over 2 per cent. of lead ash, it might be considered of the same constitution as a boiled oil. Another test, however, which seemed to indicate the presence of fish oil, was made by rubbing a few drops of the oil briskly between the palms of the hands. A very rancid olor was immediately developed. This odor, however, might have been due to the presence of the free fatty acids in the oil, resulting from the hydrolyzing action of the red lead.

At this juncture in the research it was thought that considerable light might be thrown upon the work by a very careful examination to determine the unsaponifiable constituents of the oil. It is well known that in animal oils such as menhaden oil or other fish oils there is present an unsaponifiable constituent termed cholesterol, a crystalline alcoholic body which is entirely absent in vegetable oils such as linseed oil. The latter oil, however, and most other vegetable oils contain a similar unsaponifiable body termed sitosterol. These two bodies are easily differentiated by microscopic examination. Portions of the oils were separately treated with alcohol, the alcoholic extract being saponified and afterwards treated with ether. ${ }^{3}$ The ether extract, containing the non-saponifiable bodies, was filtered and evaporated nearly to dryness, being subsequently filtered and then taken up with alcohol. Slow crystallization of the alcoholic solution resulted in the fomation of tiny crystals which were examined under the microscope. Both the original oil and the oil used in the manufacture of the red lead paint deposited crystals which when observed under the microscope seemed to be in tufts of star-like groups, probably of a monoclinic system of crystallization (pure sitosterol). These crystals did not in any way resemble the crystals which are known as cholesterol, and the above tests presented pretty conclusive proof that the oil originally used was a pure vegetable oil. A similar test, however, was made with a sample of pure menhaden oil as a blank. After the usual course of treatment, there was obtained a considerable quantity of white crystals which when observed

"Jour. Soc, Chem. Indus., 17, 954, 1898; "Chemical Technology and Analysis of Oils," etc., Lewkowitsch, vol. i, p. 470; "Oil Analysis," Gill, p. 9 I. 
under the micrincupe appeared as flat, rhombic plates which are chanateristic if the crystals of cholesterol. The melting I' (i. I.

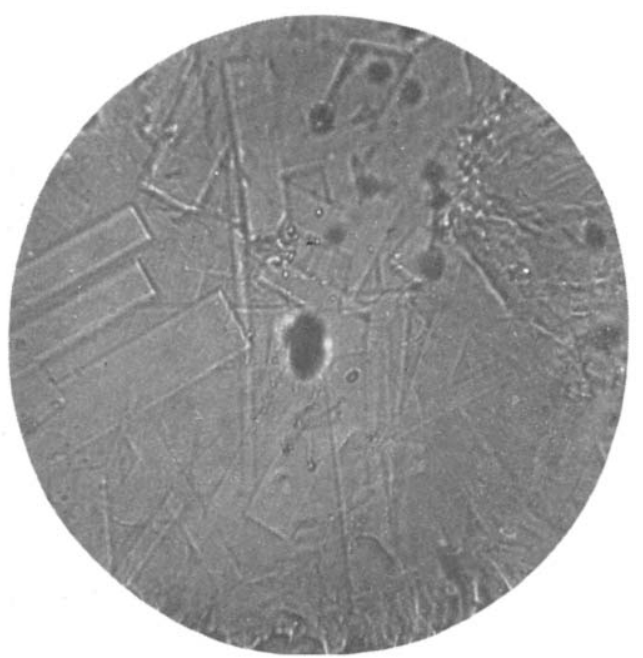

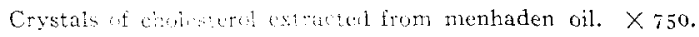

Fic. 2 .

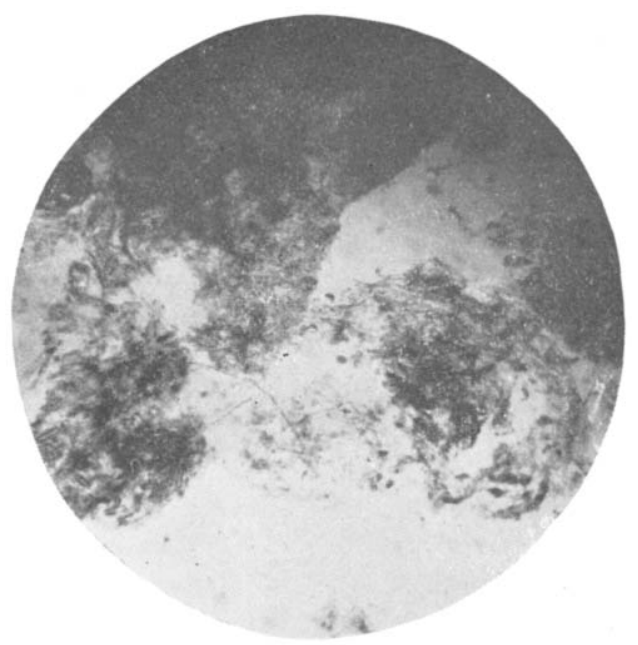

Appearance of moulti upon dried film of oil. $\times 750$.

point of the crystals from the linseed oils used in grinding the red learl paint was nut determined. the writer being unable

"Jour. Soc. Chem. Indus., 1899. 557. 
to find present any crystals which had the appearance of those found in the menhaden oil (see Fig. I).

That the peculiar condition of the red lead paint, previously described, was due to the action of some type of micro-organisms seemed evident. Recourse was therefore had to the examination of what appeared to be mould upon the surface of the red lead paint previous to its chemical examination. A portion of the film upon which the mould har grown was carefully treated with ether to wash away any undried oil. After drying, the film was placed under the microscope. The appearance of the film is shown in Fig. 2. A test-tube culture

FIG. 3 .

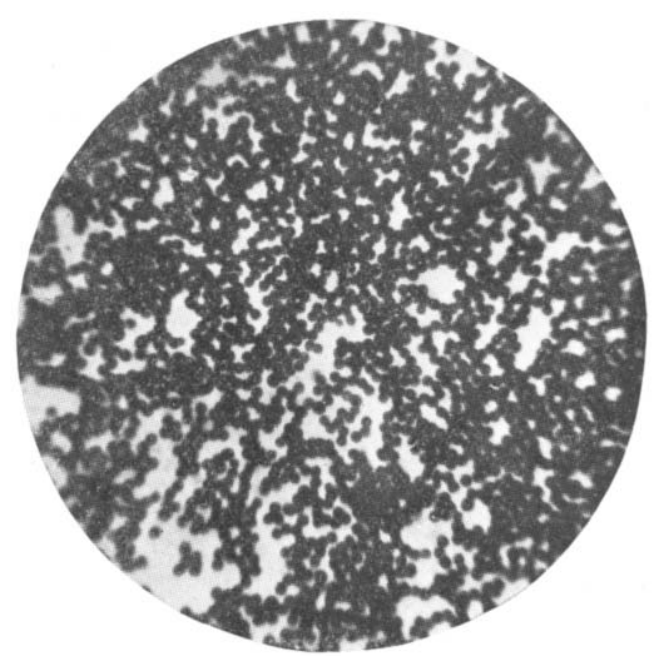

Culture of spores from linseed oil. $\times 750$.

in agar-agar was made of the monld upon the film. The surface of the agar-agar at the end of twenty-four hours was covered with a greenish mould, while there was shown to have developed downward through the jelly a peculiar white formation. Portions of both growths were examined under the microscope. The white portion was of unicellular structure, as shown in Fig. 3, while the green portion showed distinctly the mycelium with the attached cellular spores (see Fig. 4). These spores and mycelium have the distinct appearance of peniculum crustaceum. The writer is of the opinion spores which are responsible for the mildewing of 
paint may exist in nearly all samples of raw linseed oil, as accidental impurities obtained from the exterior of the crushed sced.

The writer has previously found during the course of other experiments, conducted during the past few years, that the use of 5 per cent. of solvent naphtha of $160^{\circ}$ benzol, added to the paint previous to application, prevents to a great extent the formation of mildew. On account of the xylol and toluol con-

FIG. 4 .

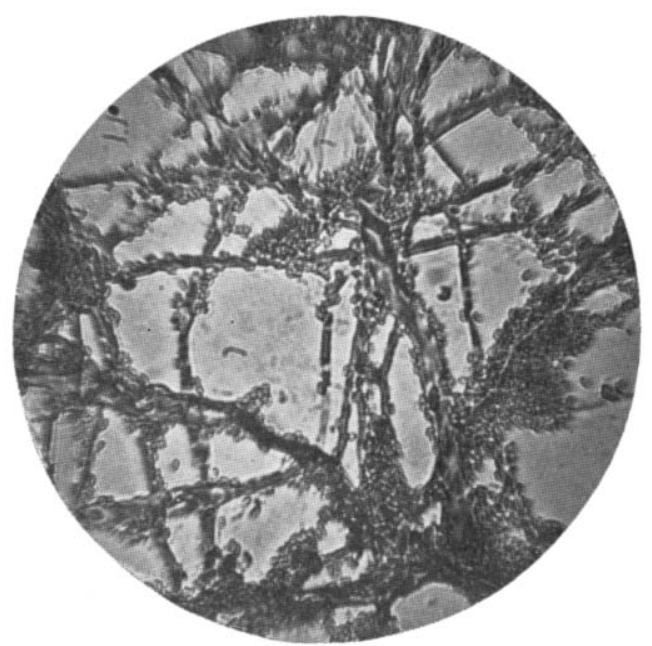

Peniculum crustaceum growing upon linseed oil. Film $\times 750$.

tent of solvent naphtha, both of these constituents having high boiling points, they are retained in the drying film and they serve to inhibit the formation of the fungus. Another material which might serve the same purpose is refined pine oil, a water white product of very high boiling point, resulting from the distillation of turpentine. Both solvent naphtha and pine oil have excellent penetrative properties and when used in an exterior paint serve to catry the pigment into the fibres of the wood to produce a firm foundation coat. 